\title{
The Mechanism of MSCs Therapy in Acute Respiratory Distress Syndrome
}

\author{
Ying Wang, Cuicui Chen, Dongni Hou and Yuanlin Song* \\ Department of Pulmonary Medicine, Zhongshan Hospital, Fudan University, China
}

\begin{abstract}
In past decades, acute respiratory distress syndrome (ARDS) has been associated with high mortality and morbidity. Although many maneuvers have been tested including tens of clinical trials, so far there is still no approved pharmacological intervention available for ARDS except protective ventilation strategy. Mesenchymal stem cells (MSCs) has shown improved survival in various ARDS animal model after administration. Here we summarized the updates of MSC derivation and purification, administration approaches, timing of MSC delivery, and mechanism of MSC therapy in order to provide a state-of-art paradigm of cell based therapy in ARDS and to facilitate the development of MSC therapy in ARDS patients.
\end{abstract}

Keywords: Mesenchymal stem cells; Acute respiratory distress syndrome; Acute lung injury; Mechanism

\section{Introduction}

The acute respiratory distress syndrome (ARDS) is a major challenge in pulmonary and critical care medicine with high morbidity and mortality [1-3]. According to a recent multi-center study on mortality from USA in 2010, the crude mortality of ICU patients declined from $31 \%$ in 1998 to $28 \%$ in 2010 [4]. However, these epidemiological surveys of incidence and mortality lacked participations of small units of the institution and ignored medical treatment units of other degrees. Also, US Centers of Disease Control announced that, ARDS, together with COPD and IPF, represented the third fatal disease following heart diseases and cancer, which has impact on 600 million people worldwide [5]. In the ICU, ARDS is responsible for up to $40 \%$ mortality of single organ injury without MODS [6].

The pathogenesis of ARDS include: out of controlled innate immune mediated inflammatory reaction in the lungs; a variety of inflammatory response promoted aggregation and activation of a large number of inflammatory factors, which stimulated the coagulation/ fibrinolysis pathway; increased alveolar epithelial and endothelial permeability; protein accumulation and formation of pulmonary edema in distal air space [7]. Thus, development of novel therapeutic strategy against ARDS need to be based on those pathophysiological changes: reduction of inflammatory factors, absorption of alveolar fluid, repair of endothelial and epithelial barrier and removal of inflammatory cells from the distal alveolar cavity. Except prone position ventilation in certain patients and low tidal volume ventilation $[8,9]$, the overall effective management of ARDS is limited. At present, there is still no available medicine for ARDS yet. However, numbers of clinical trials and preclinical validation studies are in progress. As the mesenchymal stem cells (MSCs) therapy shows promising result in recent studies, it appears an attractive approach in ARDS therapy.

There is a rising of studies, both in vitro and in vivo, suggesting that stem cells from the adult tissue are engaged in both repair and regeneration of organs, e.g. bone fracture [10], type I diabetes mellitus [11], Crohn's diseases [12], and myocardial infarction [13]. Studies of influenza infected mouse models showed that mice treated with stem cells were more likely to survive and had normal lung histology after three to five months, while in the control group, bronchiolar of mice suffered infection, and the alveolar cells presented extensive inflammation and hemorrhagic edema [14]. Considering few clinical trials using MSC in ARDS therapy were undertaking, cell-based therapy seems to be a promising regiment in future respiratory medicine [15].

Depending on their source, stem cells can be divided into embryonic and adult stem cells. For ethical and safety, most of the researches focus on adult stem cell therapy. Over the past years, a variety of bone marrow-derived cells have been found to differentiate into airway and even alveolar epithelial cells, including hematopoietic stem cells (HSCs), mesenchymal stem cells (MSCs), multipotent adult progenitor cells (MAPC), and other populations [16]. Among them, MSCs is one of the most suitable cellular therapeutic strategy due to their accessibility, differentiation potential into lung tissues, immunomodulatory ability and regeneration properties $[17,18]$. They also have excellent safety record and the ability of treating various kinds of diseases in animal models [19]. This review focuses on the mechanisms of MSCs in ARDS, and technical protocol for cell based therapy.

\section{History and Definition of MSCs}

Stem cells were first discovered by Friedenstein [20,21], who defined the bone marrow osteogenic stem cells and found their high potential as proliferation and ability as common bone precursors and cartilageforming cells. Caplan et al. [22] first used the name- mesenchymal stem cell, to define cells responsible for formatting and repairing bone and cartilage. Recently, results of meta-analysis from MEDLINE, EMBASE, BIOSIS and Web of Science have shown that MSCs substantially reduce the odds of death in animal models of ALI [23].

Mesenchymal stem cells (MSCs), also called skeletal stem cells or bone marrow stromal stem cells, are plastic adherent, non-hematopoietic cells that possess self-renewal and multi-lineage differentiation capacity [24]. MSCs are also derived from many kinds of tissues like bone marrow, adipose tissue, and placenta. The International Society of

*Corresponding author: Song $\mathrm{Y}$, Department of Pulmonary Medicine, Zhongshan Hospital, Fudan University, 180 Fenglin Road, Shanghai, China, Tel: 86-21-64041990-2963; Email: ylsong70@163.com

Received December 18, 2015; Accepted April 25, 2016; Published April 30, 2016

Citation: Wang Y, Chen C, Hou D, Song Y (2016) The Mechanism of MSCs Therapy in Acute Respiratory Distress Syndrome. J Clin Respir Dis Care 2: 115. doi: $10.4172 / 2472-1247.1000115$

Copyright: (c) 2016 Wang Y, et al. This is an open-access article distributed under the terms of the Creative Commons Attribution License, which permits unrestricted use, distribution, and reproduction in any medium, provided the original author and source are credited. 
Cellular Therapy in 2006 defined MSCs based on three criteria: (1) they must be adherent to plastic under standard tissue culture conditions; (2) they must express certain cell surface markers such as CD73, CD90, and CD105, but must not express CD45, CD34, CD14, or CD11b; and (3) they must have the capacity to differentiate into mesenchymal lineages including osteoblasts, adipocytes, and chondroblasts under in vitro conditions [25].

\section{Isolation and Differentiation of MSCs}

As is explained in definition, MSCs are plastic adherent cells which express a variety of surface markers, such as CD44, CD63, CD105, CD146. The nature of this plastic adherence can be used to identify and isolate MSCs [26]. Based on these surface markers, recent studies isolated MSCs [27] by exploring DNA microarrays that define a set of biomarkers for in vivo bone-forming capacity and "stemness" [28]. MSCs from different tissues exhibit distinct molecular phenotype and differentiation potential, which has been reported in umbilical cord, adipose tissue, skeletal muscle, periodontal ligament and even brain [29-31]. However, only bone marrow-derived MSCs [32] have demonstrated the ability to form tissues in vivo [33], while more evidence of MSCs from other tissues is still needed. Meanwhile, MSCs can differentiate into and recruit several types of lung tissues with great potential. Given their efficiency in cell therapeutics, it is necessary to find out molecular mechanisms about how lineage-specificity controls differentiation. For example, studies show that Runx2 and PPAR $\gamma$ are expressed by osteoblastic and adipocytic lineages, respectively. And expression of these transcription factors is regulated by microenvironmental conditions including hormonal, growth factors, and mechanical forces. They induce a number of intracellular signaling pathways mediating the effects on transcription factors. In addition, the role of non-coding RNAs like miRNAs may regulate the expression and function of transcription factors that determine the differentiation fate of MSCs [34]. Also, derivation and purification of MSC contribute to the effect of treatment in animals [35]. Many experiment focused on the source of bone marrow while some novel trials found human umbilical cord-derived MSC [36].

\section{Administration Method of MSCs (Table 1)}

In animal studies, intratracheal route and intravenous route are two main delivery administrating method for MSCs therapy [6]. Appropriate method depends on the animal models and the most optimal method remains unclear. The experiments with E. coli endotoxin or bacterial induced model of acute lung injury(ALI) often delivered MSCs intratracheally [37,38]. Studies using bleomycininduced [39], ischemia reperfusion-induced [40], ventilator-induced [41] and part of lipopolysaccharide(LPS)-induced [42] lung injury models administrated intravenously. Interestingly, Qin et al. [43] invented a novel method which was intra-pleural delivered. However, for practical reasons, intravenous administration is similar to clinical use and it is not easily to deliver cells into bronchia in patients with ARDS.

The way of administration may alter the timing of effect. In LPSinduced ALI models, beneficial time of MSCs through intratracheal delivery were less than 3 days while the time of effects were longer when MSCs were given intravenously. Of note, the timing of administration was within $6 \mathrm{~h}$ following ALI.

In ALI models of mice, as Zhu etc. summarized, the mean dose of MSCs typically was $29.9 \sim 10^{6}$ cells/kg BW, and in rats it was $20.3 \sim 10^{6}$ cells/kg BW, suggesting that the mean dose of MSC in ALI models in rodents typically ranges from 20 to $30 \times 10^{6} \mathrm{cells} / \mathrm{kg} \mathrm{BW}$ [6]. Although many believe that higher doses will give a prolonged response, no actual dose response has been reported in the literature. However, no dose response study has been yet published.

\section{Safety of MSCs and updated progress of MSCs therapy in ARDS}

Before clinical use of MSCs, their safety should be evaluated firstly. At present, a plenty of clinical trials of MSCs have been conducted on different diseases [44]. In addition, MSCs have been tested, with no apparent major adverse effects. According to these clinical trials for usage of MSCs, no safety issues have arisen, and no potential concerns of tumor or ectopic tissue formation have been reported. A commercial MSC preparation showed no serious adverse events (SAEs) in a phase I trial and a phase II study in patients of Crohn's disease [45]. Currently, a phase III trial has been approved by FDA for its therapeutic usage for Crohn's Disease [46]. Recently, a randomized, multi-center test of systemic MSCs use for COPD treatment showed no adverse effects or pulmonary function impairment [47].

Potential efficacy and safety of MSCs administration for the treatment of ARDS had been demonstrated in pre-clinical studies, including experiments in animals and in ex vivo perfused human lung models $[48,49]$. Recently, a study tested allogeneic adipose-derived human MSCs in 12 patients with moderate to severe ARDS and reported no infusion-related adverse events but the clinical effect with the doses of 1 million cells/kg MSCs was minor [50].

In a phase I clinical trial of MSCs in ARDS patients, no specified events or treatment-related adverse events were reported, and none of the SAEs were thought to be MSC-related [51]. In this study, bone marrow-derived human MSCs was well tolerated in nine patients with moderate to severe ARDS [51]. More researches are being conducted to determine long-term safety of MSCs.

However, limited number of MSCs homing to injured tissues still existed in many experiments [52,53]. Besides the ability of expression of chemokine receptors and adhesion molecules to mediate homing of leukocytes to inflamed tissues [54], precise role of MSCs homing is still under investigation. Also, the optimal dose of MSCs remained unclear. Highest dose of 10 million MSCs/kg demonstrated more efficient in severe lung injury in sheep [55] and this dose was well tolerated in 9 patients with moderate-to-severe ARDS [56], it remained uncertain whether the dose was optimal or not. Further studies were warranted to figure out the details of MSCs therapy.

\section{Mechanism of MSCs}

MSCs based therapy is thought to be a potential novel strategy for ARDS for a number of reasons. Firstly, MSCs are multi-potent cells with the ability of inflammation inhibition and immunomodulation. Mean MCSs are also capable of secreting multiple paracrine factors including KGF, Ang-1. They also have ability to serve as the vehicle of gene therapy, which may enhance ability of MSCs in lung injury repair in ARDS.

\section{MSCs inhibit inflammatory factors and regulate the immune system}

MSCs, which secrete a variety of active molecules, including cytokines, growth factors, anti-inflammatory peptides, and antimicrobial peptides, present significant immunity effects. They suppress activation of lymphocytes and secretion of inflammatory 


\begin{tabular}{|c|c|c|c|c|c|}
\hline & ALI model/ARDS & Delivery route & Dose( x10(6)/animal) & Mean dose $(\times 10(6) / \mathrm{kg})$ & PMID \\
\hline \multirow[t]{11}{*}{ Rats $(200-300 \mathrm{~g})$} & $\begin{array}{l}\text { LPS-induced injury } \\
\text { (intraperitoneal) }\end{array}$ & Intravenous & 2 & $6.67-10$ & 23289000 \\
\hline & & Left thigh muscle & 2 & $6.67-10$ & 20664529 \\
\hline & & Intrapleural & 1 & $3.33-5$ & 22697354 \\
\hline & Paraquat (PQ) poisoning & Intravenous & 10 & $33.3-50$ & 23257085 \\
\hline & & & & & 23902576 \\
\hline & $\begin{array}{l}\text { Ventilator-induced lung } \\
\text { injury. }\end{array}$ & Intratracheal & 4 & $13.3-20$ & 23377221 \\
\hline & & Intravenous & 2 & $6.67-10$ & 22106021 \\
\hline & $\begin{array}{l}\text { Acute pulmonary ischemia- } \\
\text { reperfusion (IR) injury }\end{array}$ & Intravenous & 1.5 & $5-7.5$ & 21781312 \\
\hline & Burn Induction & Thigh muscle & 2 & $6.67-10$ & 20573305 \\
\hline & $\begin{array}{l}\text { Bleomycin (BLM)-induced } \\
\text { acute lung injury }\end{array}$ & Intravenous & 1 & $3.33-25$ & 20137099 \\
\hline & & & & & 18589176 \\
\hline \multirow[t]{17}{*}{ Mice $(30-35 \mathrm{~g})$} & $\begin{array}{l}\text { LPS-induced injury( } \\
\text { intratracheal) }\end{array}$ & Intratracheal & 0.75 & $21.4-25$ & 17641052 \\
\hline & & & & & 23360775 \\
\hline & & & 0.25 & $7.13-8.33$ & 23023971 \\
\hline & & & 0.5 & $14.26-16.66$ & 21569482 \\
\hline & & & 1 & $28.52-33.33$ & 21691076 \\
\hline & & Intravenous & 1 & $28.52-33.33$ & 23760104 \\
\hline & & Jugular venous canula & 0.25 & $7.13-8.33$ & 17803352 \\
\hline & intraperitoneal & Intravenous & & & \\
\hline & & & 0.5 & $14.26-16.66$ & 17416739 \\
\hline & & & 1 & $28.52-33.33$ & 23760104 \\
\hline & $\begin{array}{l}\text { Escherichia coli-induced } \\
\text { acute lung injury }\end{array}$ & Intratracheal & 1 & $28.6-33.3$ & 21843339 \\
\hline & & & & & 20945332 \\
\hline & $\begin{array}{l}\text { Bleomycin (BLM)-induced } \\
\text { acute lung injury }\end{array}$ & Intravenous & 1 & $28.6-33.3$ & 23207668 \\
\hline & & & & & 19497992 \\
\hline & $P$. aeruginosa & Intravenous & 1 & $28.6-33.3$ & 22427530 \\
\hline & Polidocanol & Intratracheal & 1 & $28.6-33.3$ & 19606934 \\
\hline & $\begin{array}{l}\text { Cecal ligation and } \\
\text { puncture }\end{array}$ & Intravenous & 1 & $28.6-33.3$ & 19098906 \\
\hline Rabbits（2 kg） & $\begin{array}{l}\text { Early stage of smoke } \\
\text { inhalation injury }\end{array}$ & Intravenous & 10 & & 25214973 \\
\hline Sheep(30-40 kg) & Pseudomonas aeruginosa & Intravenous & & $5-10$ & 24891325 \\
\hline Humans' clinical trial & ARDS & Intravenous & & $1-10$ & 24708472 \\
\hline
\end{tabular}

Table 1: Studies including animal models and clinical trials in ARDS with MSCs treatment.

factors (TNF-a, IFNc), and induce the release of anti-inflammatory factors (IL-10, IL-4) [57-59]. These effects increase the clearance of alveolar fluid and reduce inflammation, thus reverse the lung injury [60,61]. In addition to releasing soluble anti-inflammatory factors, the MSCs transfer microvesicles containing mitochondria, protein, and microRNA to other cells [62]. Inflammatory cytokines are thought to contribute to diffuse alveolar damage (DAD), in part by disrupting endothelial functions at capillary-alveolar junction, which leads to junction breaching, type II cell dysfunction, and surfactants loss. LPS-induced ALI model shows that after $24 \mathrm{~h}$ of MSC administration, the systemic inflammation is reduced because of many kinds of inflammatory mediators [63]. Studies also show that endothelial FoxM1 induces vascular repair as well as inflammation reduction [64]. Additionally, MSC reduced mortality in a mouse model of gramnegative peritonitis and sepsis, and the improvement in bacterial clearance was mediated through enhancement of phagocytic activity of peripheral blood mononuclear cells [65]. Furthermore, analysis of expression of major antimicrobial peptides indicates that one of the factors responsible for the antimicrobial activity of MSC against Gramnegative bacteria is human cathelicidin antimicrobial peptide, hCAP18/LL-37 [37].

Importantly, MSCs can modulate innate and adaptive immune cells. First MSCs promote repolarization of monocytes and macrophages from type 1 to type 2 phenotype, which is characterized by high level of interleukin-10 secretion. Interleukin-10 blocks polymorphonuclear neutrophil influx into the injured tissue and prevents further damage [35,66-69]. Second, MSCs own the ability of interfering with dendritic cells differentiation, maturation and function, by skewing them towards a regulatory phenotype and decreasing their capacity to induce $\mathrm{T}$ cells activation. Third, they also impair cytotoxic activity, cytokine production and granzyme B release of natural killer cells [70,71]. Fourth, MSCs suppress $\mathrm{T}$ cell activation and proliferation and decrease their response by shifting them from Th1 to Th2 immune response [72]. Moreover, MSCs have been shown to inhibit the differentiation of naive $\mathrm{T}$ cells into Th17 cells and prevent the 
secretion of pro-inflammatory cytokines by Th17 cells [73]. MSCs also promote induction of immunosuppressive $\mathrm{T}$ regulatory cells partially by reprogramming Th17 cells into T regulatory cells $[35,74,75]$.

\section{Restoring the integrity of pulmonary vascular barrier}

More recent data suggest that factors released by MSCs influence the balance of permeability of alveolar-capillary induce leak of endothelial fluid $[76,77]$. Some reports of animal experiments describe that intrapulmonary MSC administration method can improve survival rate, by reducing pulmonary edema formation [48] and promoting repair of epithelium and endothelium [78]. Researchers have compiled adult stem cell therapy of the main clinical and experimental researches, which suggests that MSC on lung development and repair and remodeling of the beneficial effects and the side of secreted factors can effectively reduce inflammation and promote tissue repair [79]. And these factors have been evident in cultured human alveolar epithelial cells [80], which helped to restore the integrity of pulmonary vascular barrier. Furthermore, circumstantial evidence of humans and mice shows that ARDS may trigger the regeneration of pulmonary tissue. Meanwhile, the stem cells may play a role in this remarkable process, which yielded a defined set of cloned human airway stem cells marked by p63 expression [81].

Mechanisms may also involve the protection and repair of the epithelial barrier. MSCs releases angiogenesis -1 that prevents formation of actin stress fibers and disorganization of claudin 18 , which is closely connected with the function to destroy epithelial cells, induce S1P and inhibit the internalization of endothelial VE-cadherin, through suppression of NF- $\mathrm{KB}$ activity. In experiment, stem cells use connecxin (connexin-43-based gap junctional channels) to attach to the walls of the alveoli and then translocate alveolar epithelial cell mitochondria damaged by endotoxin, thus help alveolar ATP generation, surface active agent production, and epithelial barrier restoration [62]. In addition, refilling the lost lung cells can restore the function of lung in the short term [82]. Researchers observed that cell therapy resulted in hyperplasia of type II cells and repair of the damaged epithelium [83].

Alveolar fluid reabsorption is based on sodium and chloride channels of the alveolar epithelial cells, injury of which is related to the epithelial cell damage, necrosis and apoptosis, caused by ARDS. Recovery of alveolar fluid reabsorption mainly depends on reconstruction of the epithelial barrier using new alveolar epithelium produced by alveolar type II epithelial cells. There is the evidence that primitive cells from the junction of bronchial cells promote the activation of repair device; the expression of alpha beta 64 - primitive cells [84] and c-kit + lung stem cell 204 is involved in this case. Some studies found that endothelial FOXM1 mediated bone marrow progenitor cells and induced inflammatory vascular repair after lung injury by restoring its integrity and accelerating the dissipation of inflammation [64].

\section{MSCs engraftment in epithelium and recruitment in endothelial cells}

Intravenous infusion is an ideal method of MSCs administration because it makes cells entrapped in lung capillary beds [85]. In addition, MSCs have the ability to transport to the inflammatory sites and migrate through the injured endothelium into the lung tissue, which is crucial for the treatment of ARDS [86]. This situation is driven by the connection between the chemokines released by injured sites and the receptors expressed by MSCs. While both embryonic and adult stem cells can be induced to express phenotypic markers of airway and/ or alveolar epithelial cells in vitro, engraftment of airway or alveolar epithelium by stem or progenitor cells following systemic administration is rare and of unclear physiologic or therapeutic significance $[15,16,87]$. Nevertheless, MSCs respond, migrate, and facilitate repair of damaged tissue making them an attractive candidate for both prevention and treatment of lung disease.

The mechanisms of engraftment are not well understood. Both in vitro and in vivo experiments showed that the fusion of stem cells with other cells might be one approach. Other studies suggested that stem cells might acquire phenotypes of epithelial cells, which express markers induced by soluble factors from injured lung epithelium, possibly activated by Wnt/ $\beta$-catenin pathway $[89,90]$ or JNK-P38 signaling pathway [91]. One recent study showed that phenotypic change is induced by the release of membrane-derived microvesicles, which mediate communications between cells by transferring miRNAs [92,93]. Moreover, recent study showed transplantation of MSCs could improve lung injury through increasing autophagy-related signaling molecules. This result supports the hypothesis that MSCs stimulate autophagy in OGD-injured HPMVECs, at least in part via the PI3K/ Akt signalling pathway[94,95].

Circulating or systemically administered stem or progenitor cells can be recruited into lungs and many of them initially localize in injured lung tissue [96-98]. In the meantime, the timing of cell administration after lung injury affects their recruitment and differentiation. Also, systemic administration of MSCs 4 hours after lung injury resulted in apparent engraftment as epithetical and endothelial cells [96] while administration at the later time resulted in engraftment as interstitial cells $[96,99]$. MSCs can secrete angiopoietin-1, which is a soluble factor capable of improving endothelial permeability and enhancing the endothelium survival and the vascular stabilization [100]. Meanwhile, MSCs inhibit the inflammation and preserve the integrity of vascular endothelium in the lungs after hemorrhagic shock [101].

\section{Paracrine-modulating factors and KGF (Table 2)}

It was firstly demonstrated by observing that systemic administration of MSCs were able to inhibit expression of several inflammatory cytokines in models of ALI [102]. In LPS-induced ARDS, $24 \mathrm{~h}$ after MSCs administration, inflammatory response was reduced because of release of the anti-inflammatory factors [63]. Interestingly, similar results were observed while only the medium of MSCs was used [49]. Despite the presence of MSCs in injured place, MSCs exert paracrine actions, secreting growth factors and cytokines. Indeed, paracrinemodulating factors secreted by MSCs seem to contribute to injury repair rather than MSC engraftment [81]. Several studies identified that the level of engraftment in the lung is limited, and in vivo studies showed limited replacement of injured tissue. Several studies identified that the level of engraftment in the lung is limited, and in vivo studies showed limited replacement of injured tissue. Therapeutic effects were attributed to paracrine, which is an ability to secrete soluble factors that modulate immune responses [103], and only a small number of pulmonary MSCs engraftment was observed [83].

Low levels of MSC cell engraftment and an even greater preventative effect of delivery of cell-free MSC-conditioned media support the importance of paracrine effect. So, to strengthen immune modulation, a variety of studies use these cytokines obtained from MSC cultures in hypoxia condition instead of MSCs. These media, including interleukin (IL-6 and IL-1) and growth factors (FGF-2, FGF-7, and VEGF-A), were found to promote attenuation of inflammatory response and stimulate endothelial cell migration, contributing to repair of vascular tissue 
in an ischemic muscle injury model [104]. Meanwhile, MSCs secrete chemokines and growth factors (TGFB, TSG6, PGE2) that stimulate endogenous/resident cells, exhibit anti-apoptotic and immunomodulatory effects as well as enhance vascular genesis [105,106] and the stimulation of all these secreted factors triggers the role of epithelial cell repair [107]. Moreover, recent in vivo studies showed a novel mechanism in which micro-vesicles released from MSC deliver messenger RNA (mRNA), micro RNA or proteins that reprogram the injured cells or induce secretion of cyto-protective factors, which has been demonstrated in ALI [108]. Above all, while systemically injected MSC can be entrapped in the lungs [109,110], they still make a positive influence through secretion of factors [111].

Secretion of paracrine factors that can regulate lung permeability and decrease inflammation by MSCs, is thought to be exerted in the treatment of ARDS. Keratinocyte growth factor (KGF), the role of which in acute lung injury has been studied since 1990s, has been extensively used in ARDS. Its characteristic of being stimulated by inflammatory cytokines and up-regulating the expression of the epithelial repair, may be one of the possible mechanisms for the MSCs treatment of ARDS, with consistent findings from other studies [112].

In animal studies, KGF reduces lung injury and increases the proliferation and repair of epithelial cells. Many studies demonstrated that KGF up-regulates the expression of epithelial sodium channel gene and enhances Na-K-ATPase activity to increase alveolar fluid clearance [113]. In addition, KGF increases the concentrations of antiinflammatory cytokines IL-1ra and epithelial repair medium (MMP-9) in alveolar, and enhances macrophage function in necrotic cells and bacteria (GM-CSF) scavenging [114]. KGF mediated effects were not only found in animal models but also in clinical trials. Phase II clinical trials in Britain found that compared with the placebo group, KGF can increase the oxygen indexes of ARDS patients [115].

Similar to KGF, KGF-2, also named FGF-10 (fibroblast growth factor-10), is the heparin-binding protein expressed by MSCs, which binds to FGF receptor 2-IIIb expressed on epithelial cells. KGF-2 mediates interactions between epithelium and MSCs, which is crucial for lung development [116,117]. KGF-2 also prevents lung injury [118120]. Furthermore, KGF-2 has no in vitro or in vivo effects on epitheliallike tumors [121], which validates the safety of KGF-2. Studies assessed the possibility of exogenous KGF-2 through directly in vivo experiments. Intratracheal administration of KGF-2 attenuates lung injury induced by LPS, suggesting that KGF- 2 may reduce acute lung injury [122]. And pre-treatment with KGF-2 showed improvement of lung edema and inflammation compared with high-volume zero positive end-expiratory pressure (HVZP) alone, suggesting that KGF-2 might be considered as a promising prevention for human ventilatorinduced lung injury (VILI) or other acute lung injury diseases [123]. Most recently, MSC-derived microvesicles have been found to protect

\begin{tabular}{|c|c|c|c|}
\hline $\begin{array}{c}\text { Endothelial and } \\
\text { epithelial growth } \\
\text { factors }\end{array}$ & Immunomodulation & $\begin{array}{c}\text { Anti- } \\
\text { inflammation } \\
\text { and } \\
\text { antimicrobial } \\
\text { peptides }\end{array}$ & $\begin{array}{c}\text { Reduction } \\
\text { of alveolar } \\
\text { epithelial } \\
\text { permeability }\end{array}$ \\
\hline FGF-10 & IDO & IL1RN & ANGPT1 \\
\hline KGF & NO & ANGPT1 & KGF \\
\hline HGF & PGE2 & KGF & HGF \\
\hline IL-6 & TGF-b & HGF & \\
\hline & TSG-6 & Lipoxin-A4 \\
\hline
\end{tabular}

Table 2: Variety of active factors secreted by MSCs.
LPS-induced ALI through delivering KGF mRNA into the injured alveolus [124]. Also, recent study showed a novel mechanism of KGF2 that could easily isolate the lower respiratory tract of rats to lungresident MSCs (LR-MSCs). Additionally, they illustrated that the LRMSCs isolated from KGF-2 pretreated rats were protective against LPSinduced acute lung injury. Collectively, KGF-2 plays an important role in LR-MSCs proliferation and mobilization and in the organ specific protective effects against acute lung injury [125].

\section{Gene therapy}

MSCs have ability to serve as the vehicle of gene therapy in treatment of ARDS due to adhesion and proliferation properties [126]. Researches indicated that MSCs could deliver gene through viral vector based transplantation. While MSCs were transduced and maintained their own characteristics, including accessibility, proliferation and compatibility, it could be an ideal carrier to transfer gene to target tissues. Many studies demonstrated that transduced MSC could engraft and differentiate into lung epithelial cells with target gene expression $[39,76,127]$. Also, together with other types of cells, MSC could fuse with one of them to form a heterokaryon, converting its gene expression patterns to that fusion partner [128]. An experimental study found that $20-50 \%$ of lung epithelial cells derived from such cell fusion [129].

Additionally, combination of gene therapies showed further improved efficiency compared to use MSC alone. For instance, in an ALI model, administration of MSCs transfected with angiopoietin-1 improved alveolar inflammatory and permeability result, comparing with MSCs alone [76,80]. Furthermore, an in vivo mouse model showed that the LPS-induced lung injury was remarkably improved in the group treated with MSCs carrying FGF2 (MSCs-FGF2), including reduced histopathological index and level of inflammatory cytokines, suggesting that MSCs and FGF2 have a synergistic effect [130]. Although macrophages play a role in ARDS, the MSCs only weakly modulate macrophage function. However, researchers found MSCs stably transfected with a vector expressing negative inhibitor of CCL2 could induce macrophage activation. This experiment showed that MSCs can be used for drug delivery. Moreover, MSC-based endothelial locus- 1 gene therapy has been established [131], which may enhance ability of MSCs repairing lung injury in ARDS [132].

\section{Conclusion}

ARDS has been studied so far for more than 40 years in epidemiology, risk factors, pathogenesis, diagnosis, treatment and prognosis. In spite of important developments of novel therapies, the mortality of ARDS is still high due to the complexity of the disease itself. Thus, ARDS becomes one of the leading lethal diseases in respiratory field. Exploring new treatments options based on pathogenesis is the future direction of ARDS research. Stem cells, especially MSCs, are the state-of-art progress of recent researches in ARDS. The mechanisms of MSCs therapy includes reducing inflammation, repairing lung tissue and the paracrine ability. Given the current findings, a promise is held for new breakthroughs in ARDS by cell based therapy.

\section{References}

1. Bice T, Li G, Malinchoc M, Lee AS, Gajic O (2011) Incidence and risk factors of recurrent acute lung injury.Crit Care Med 39: 1069-1073.

2. Zhu YF, Xu F, Lu XL, Wang Y, Chen JL, et al. (2012) Mortality and morbidity of acute hypoxemic respiratory failure and acute respiratory distress syndrome in infants and young children.Chin Med J (Engl) 125: 2265-2271.

3. Aisiku IP, Yamal JM, Doshi P, Rubin ML, Benoit JS, et al. (2016) The incidence of ARDS and associated mortality in severe TBI using the Berlin definition.J Trauma Acute Care Surg 80: 308-312. 
4. Aliotta JM, Passero M, Meharg J, Klinger J, Dooner MS, et al. (2005) Stem cells and pulmonary metamorphosis: new concepts in repair and regeneration.J Cell Physiol 204: 725-741.

5. Tansey CM, Louie M, Loeb M, Gold WL, Muller MP, et al. (2007) One-year outcomes and health care utilization in survivors of severe acute respiratory syndrome.Arch Intern Med 167: 1312-1320.

6. Zhu YG, Hao Q, Monsel A, Feng XM, Lee JW (2013) Adult stem cells for acute lung injury: remaining questions and concerns.Respirology 18: 744-756.

7. Suresh R, Kupfer Y, Tessler S (2000) Acute respiratory distress syndrome.N Engl J Med 343: 660-661.

8. Guérin C, Reignier J, Richard JC, Beuret P, Gacouin A, et al. (2013) Prone positioning in severe acute respiratory distress syndrome.N Engl J Med 368: 2159-2168.

9. Needham DM, Yang T, Dinglas VD, Mendez-Tellez PA, Shanholtz C, et al. (2015) Timing of low tidal volume ventilation and intensive care unit mortality in acute respiratory distress syndrome. A prospective cohort study.Am J Respir Crit Care Med 191: 177-185.

10. Gangji V, Hauzeur JP (2005) Treatment of osteonecrosis of the femoral head with implantation of autologous bone-marrow cells. Surgical technique.J Bone Joint Surg Am 87 Suppl 1: 106-112.

11. Bhansali A, Asokumar P, Walia R, Bhansali S, Gupta V, et al. (2014) Efficacy and safety of autologous bone marrow-derived stem cell transplantation in patients with type 2 diabetes mellitus: a randomized placebo-controlled study. Cell Transplant 23: 1075-1085.

12. Duijvestein M, Vos AC, Roelofs $H$, Wildenberg ME, Wendrich BB, et al. (2010) Autologous bone marrow-derived mesenchymal stromal cell treatment for refractory luminal Crohn's disease: results of a phase I study.Gut 59: 1662 1669.

13. Chen S L, Fang W W, Ye F, Liu Y H, Qian J, et al. (2004) Effect on left ventricular function of intracoronary transplantation of autologous bone marrow mesenchymal stem cell in patients with acute myocardial infarction. Am J Cardiol 94: 92-95.

14. Kumar P A, Hu Y, Yamamoto Y, Hoe N B, Wei T S, et al. (2011)Distal airway stem cells yield alveoli in vitro and during lung regeneration following H1N1 influenza infection. Cell 147: 525-538.

15. Weiss DJ, Kolls JK, Ortiz LA, Panoskaltsis-Mortari A, Prockop DJ (2008) Stem cells and cell therapies in lung biology and lung diseases.Proc Am Thorac Soc 5: 637-667.

16. Sueblinvong V, Loi R, Eisenhauer PL, Bernstein IM, Suratt BT, et al. (2008) Derivation of lung epithelium from human cord blood-derived mesenchymal stem cells.Am J Respir Crit Care Med 177: 701-711.

17. Nauta AJ, Fibbe WE (2007) Immunomodulatory properties of mesenchymal stromal cells.Blood 110: 3499-3506.

18. Zhao S, Wehner R, Bornhauser M, Wassmuth R, Bachmann M, et al. (2010) Immunomodulatory properties of mesenchymal stromal cells and their therapeutic consequences for immune-mediated disorders. Stem Cells Dev 19: 607-614

19. Lepperdinger G, Brunauer R, Jamnig A, Laschober G, Kassem M (2008) Controversial issue: is it safe to employ mesenchymal stem cells in cell-based therapies?Exp Gerontol 43: 1018-1023.

20. Friedenstein AJ, Chailakhjan RK, Lalykina KS (1970) The development of fibroblast colonies in monolayer cultures of guinea-pig bone marrow and spleen cells.Cell Tissue Kinet 3: 393-403.

21. Friedenstein AJ, Chailakhyan RK, Gerasimov UV (1987) Bone marrow osteogenic stem cells: in vitro cultivation and transplantation in diffusion chambers.Cell Tissue Kinet 20: 263-272.

22. Caplan Al (1991) Mesenchymal stem cells.J Orthop Res 9: 641-650.

23. Mclntyre LA1,2,3, Moher D2,3, et al. (2016) Efficacy of Mesenchymal Stromal Cell Therapy for Acute Lung Injury in Preclinical Animal Models: A Systematic Review.PLoS One 11: e0147170.

24. Bianco P, Cao X, Frenette PS, Mao JJ, Robey PG, et al. (2013) The meaning, the sense and the significance: translating the science of mesenchymal stem cells into medicine.Nat Med 19: 35-42.

25. Dominici M, Le Blanc K, Mueller I, Slaper-Cortenbach I, Marini F, et al. (2006)
Minimal criteria for defining multipotent mesenchymal stromal cells. The International Society for Cellular Therapy position statement. Cytotherapy 8 : 315-317.

26. Kassem M, Mosekilde L, and Eriksen E F (1993) 1,25-dihydroxyvitamin D3 potentiates fluoride-stimulated collagen type I production in cultures of human bone marrow stromal osteoblast-like cells. J Bone Miner Res 8: 1453-1458.

27. Houlihan DD, Mabuchi Y, Morikawa S, Niibe K, Araki D, et al. (2012) Isolation of mouse mesenchymal stem cells on the basis of expression of Sca-1 and PDGFR-ît.Nat Protoc 7: 2103-2111.

28. Tormin A, Li O, Brune JC, Walsh S, Schütz B, et al. (2011) CD146 expression on primary nonhematopoietic bone marrow stem cells is correlated with in situ localization. Blood 117: 5067-5077.

29. Bianco P, Riminucci M, Gronthos S, Robey PG (2001) Bone marrow stroma stem cells: nature, biology, and potential applications.Stem Cells 19: 180-192.

30. Kermani AJ, Fathi F, Mowla SJ (2008) Characterization and genetic manipulation of human umbilical cord vein mesenchymal stem cells: potential application in cell-based gene therapy.Rejuvenation Res 11: 379-386.

31. Harkness L, Mahmood A, Ditzel N, Abdallah B M, Nygaard J V, et al. (2011) Selective isolation and differentiation of a stromal population of human embryonic stem cells with osteogenic potential. Bone 48: 231-241.

32. Lian Q, Zhang Y, Zhang J, Zhang HK, Wu X, et al. (2010) Functiona mesenchymal stem cells derived from human induced pluripotent stem cells attenuate limb ischemia in mice. Circulation 121: 1113-1123.

33. Sacchetti B, Funari A, Michienzi S, Di Cesare S, Piersanti S, et al. (2007) Self-renewing osteoprogenitors in bone marrow sinusoids can organize a hematopoietic microenvironment. Cell 131: 324-336.

34. Krause DS, Theise ND, Collector MI, Henegariu O, Hwang S, et al. (2001) Multi-organ, multi-lineage engraftment by a single bone marrow-derived stem cell.Cell 105: 369-377.

35. Monsel A, Zhu Y G, Gennai S, Hao Q, Liu J, et al.(2014)Cell-based therapy for acute organ injury: preclinical evidence and ongoing clinical trials using mesenchymal stem cells. Anesthesiology 121: 1099-1121.

36. Li J, Li D, Liu X, Tang S, Wei F (2012) Human umbilical cord mesenchymal stem cells reduce systemic inflammation and attenuate LPS-induced acute lung injury in rats. J Inflamm (Lond) 9: 33.

37. Krasnodembskaya A, Song Y, Fang X, Gupta N, Serikov V, et al. (2010) Antibacterial effect of human mesenchymal stem cells is mediated in part from secretion of the antimicrobial peptide LL-37.Stem Cells 28: 2229-2238.

38. Kim E S, Chang Y S, Choi S J, Kim J K, Yoo H S, et al. (2011) Intratracheal transplantation of human umbilical cord blood-derived mesenchymal stem cells attenuates Escherichia coli-induced acute lung injury in mice. Respir Res 12: 108 .

39. Aguilar S, Scotton CJ, Mcnulty K, Nye E, Stamp G, et al. (2009) Bone marrow stem cells expressing keratinocyte growth factor via an inducible lentivirus protects against bleomycin-induced pulmonary fibrosis. PLoS One 4: e8013.

40. Chen S, Chen L, Wu X, Lin J, Fang J, et al. (2012) Ischemia postconditioning and mesenchymal stem cells engraftment synergistically attenuate ischemia reperfusion-induced lung injury in rats. J Surg Res 178: 81-91.

41. Chimenti L, Luque T, Bonsignore MR, Ramírez J, Navajas D, et al. (2012) Pretreatment with mesenchymal stem cells reduces ventilator-induced lung injury. Eur Respir J 40: 939-948.

42. Herzmann N, Salamon A, Fiedler T, Peters K (2016) Analysis of migration rate and chemotaxis of human adipose-derived mesenchymal stem cells in response to LPS and LTA in vitro.Exp Cell Res 342: 95-103.

43. Qin ZH, Xu JF, Qu JM, Zhang J, Sai Y, et al. (2012) Intrapleural delivery of MSCs attenuates acute lung injury by paracrine/endocrine mechanism.J Cell Mol Med 16: 2745-2753

44. Giordano A, Galderisi U, Marino IR (2007) From the laboratory bench to the patient's bedside: an update on clinical trials with mesenchymal stem cells.J Cell Physiol 211: 27-35.

45. Sueblinvong V, Weiss DJ (2009) Cell therapy approaches for lung diseases: current status.Curr Opin Pharmacol 9: 268-273.

46. Lanzoni G, Roda G, Belluzzi A, Roda E, Bagnara GP (2008) Inflammatory bowel disease: Moving toward a stem cell-based therapy.World J Gastroenterol 14: 4616-4626. 
47. Weiss DJ, Casaburi R, Flannery R, LeRoux-Williams M, Tashkin DP (2013) A placebo-controlled, randomized trial of mesenchymal stem cells in COPD. Chest 143: 1590-1598

48. Gupta N, Su X, Popov B, Lee JW, Serikov V, et al. (2007) Intrapulmonary delivery of bone marrow-derived mesenchymal stem cells improves survival and attenuates endotoxin-induced acute lung injury in mice.J Immunol 179 1855-1863.

49. Lee JW, Fang X, Gupta N, Serikov V, Matthay MA (2009) Allogeneic human mesenchymal stem cells for treatment of $E$. coli endotoxin-induced acute lung injury in the ex vivo perfused human lung.Proc Natl Acad Sci U S A 106: 1635716362.

50. Zheng G, Huang L, Tong H, Shu Q, Hu Y, et al.(2014)Treatment of acute respiratory distress syndrome with allogeneic adipose-derived mesenchymal stem cells: a randomized, placebo-controlled pilot study. Respir Res.15:39

51. Wilson JG, Liu KD2, Zhuo H3, Caballero L4, McMillan M4, et al. (2015) Mesenchymal stem (stromal) cells for treatment of ARDS: a phase 1 clinical trial.Lancet Respir Med 3: 24-32.

52. Yang X, Balakrishnan I, Torok-Storb B, and Pillai M M(2012)Marrow Stromal Cell Infusion Rescues Hematopoiesis in Lethally Irradiated Mice despite Rapid Clearance after Infusion. Adv Hematol.2012:142530.

53. Jia J, Tian Q, Ling S, Liu Y, Yang S, et al. (2013) miR-145 suppresses osteogenic differentiation by targeting Sp7.FEBS Lett 587: 3027-3031.

54. Wu Y, Zhao RC (2012) The role of chemokines in mesenchymal stem cell homing to myocardium.Stem Cell Rev 8: 243-250.

55. Asmussen S, Ito H, Traber DL, Lee JW, Cox RA, et al. (2014) Human mesenchymal stem cells reduce the severity of acute lung injury in a sheep model of bacterial pneumonia. Thorax 69: 819-825.

56. Walter J, Ware LB, Matthay MA (2014) Mesenchymal stem cells: mechanisms of potential therapeutic benefit in ARDS and sepsis.Lancet Respir Med 2: 1016-1026.

57. Ortiz LA, Dutreil M, Fattman C, Pandey AC, Torres G, et al. (2007) Interleukin 1 receptor antagonist mediates the antiinflammatory and antifibrotic effect of mesenchymal stem cells during lung injury.Proc Natl Acad Sci U S A 104: 11002-11007.

58. Iyer SS, Rojas M (2008) Anti-inflammatory effects of mesenchymal stem cells: novel concept for future therapies. Expert Opin Biol Ther 8: 569-581.

59. Uccelli A, Moretta L, Pistoia V (2008) Mesenchymal stem cells in health and disease.Nat Rev Immunol 8: 726-736.

60. Matthay MA, Goolaerts A, Howard JP, Lee JW (2010) Mesenchymal stem cells for acute lung injury: preclinical evidence.Crit Care Med 38: S569-573.

61. Matthay MA, Thompson BT, Read EJ, McKenna DH Jr, Liu KD, et al. (2010) Therapeutic potential of mesenchymal stem cells for severe acute lung injury. Chest 138: 965-972.

62. Islam MN, Das SR, Emin MT, Wei M, Sun L, et al. (2012) Mitochondrial transfer from bone-marrow-derived stromal cells to pulmonary alveoli protects against acute lung injury.Nat Med 18: 759-765.

63. Rojas M, Xu J, Woods CR, Mora AL, Spears W, et al. (2005) Bone marrowderived mesenchymal stem cells in repair of the injured lung.Am J Respir Cell Mol Biol 33: 145-152.

64. Zhao Y D, Huang X, Yi F, Dai Z, Qian Z, et al. (2014) Endothelial FoxM1 mediates bone marrow progenitor cell-induced vascular repair and resolution of inflammation following inflammatory lung injury. Stem Cells.32:1855-1864.

65. Krasnodembskaya A, Samarani G, Song Y, Zhuo H, Su X, et al. (2012) Human mesenchymal stem cells reduce mortality and bacteremia in gram-negative sepsis in mice in part by enhancing the phagocytic activity of blood monocytes. Am J Physiol Lung Cell Mol Physiol 302: L1003-1013.

66. Nauta AJ, Kruisselbrink AB, Lurvink E, Willemze R, Fibbe WE (2006) Mesenchymal stem cells inhibit generation and function of both CD34+-derived and monocyte-derived dendritic cells. J Immunol 177: 2080-2087.

67. Kim J, Hematti P (2009) Mesenchymal stem cell-educated macrophages: a novel type of alternatively activated macrophages. Exp Hematol 37: 1445-1453.

68. Zhang Q Z, Su W R, Shi S H, Wilder-Smith P, Xiang A P, et al.(2010) Human gingiva-derived mesenchymal stem cells elicit polarization of $\mathrm{m} 2$ macrophages and enhance cutaneous wound healing. Stem Cells.28:1856-1868.
69. Ionescu L, Byrne RN, van Haaften T, Vadivel A, Alphonse RS, et al. (2012) Stem cell conditioned medium improves acute lung injury in mice: in vivo evidence for stem cell paracrine action.Am J Physiol Lung Cell Mol Physiol 303: L967-977.

70. Poggi A, Prevosto C, Massaro AM, Negrini S, Urbani S, et al. (2005) Interaction between human NK cells and bone marrow stromal cells induces NK cell triggering: role of NKp30 and NKG2D receptors.J Immunol 175: 6352-6360.

71. Monsel A, Lu Q, Le Corre M, Brisson H, Arbelot C, et al. (2016) Taperedcuff Endotracheal Tube Does Not Prevent Early Postoperative Pneumonia Compared with Spherical-cuff Endotracheal Tube after Major Vascular Surgery: A Randomized Controlled Trial. Anesthesiology.

72. Di Nicola M, Carlo-Stella C, Magni M, Milanesi M, Longoni PD, et al. (2002) Human bone marrow stromal cells suppress T-lymphocyte proliferation induced by cellular or nonspecific mitogenic stimuli.Blood 99: 3838-3843.

73. Ghannam S, Pène J, Moquet-Torcy G, Jorgensen C, Yssel H (2010) Mesenchymal stem cells inhibit human Th17 cell differentiation and function and induce a T regulatory cell phenotype. J Immunol 185: 302-312.

74. Sun J, Han Z B, Liao W, Yang S G, Yang Z, et al.(2011)Intrapulmonary delivery of human umbilical cord mesenchymal stem cells attenuates acute lung injury by expanding CD4+CD25+ Forkhead Boxp3 (FOXP3)+ regulatory T cells and balancing anti- and pro-inflammatory factors. Cell Physiol Biochem 27: 587-596.

75. Tatara R, Ozaki K, Kikuchi Y, Hatanaka K, Oh I, et al. (2011) Mesenchymal stromal cells inhibit Th17 but not regulatory T-cell differentiation.Cytotherapy 13: 686-694.

76. Mei SH, McCarter SD, Deng Y, Parker CH, Liles WC, et al. (2007) Prevention of LPS-induced acute lung injury in mice by mesenchymal stem cells overexpressing angiopoietin 1.PLoS Med 4: e269.

77. Xu J, Qu J, Cao L, Sai Y, Chen C, et al. (2008) Mesenchymal stem cell-based angiopoietin-1 gene therapy for acute lung injury induced by lipopolysaccharide in mice.J Pathol 214: 472-481.

78. Prota L F, Lassance R M, Maron-Gutierrez T, Castiglione R C, Garcia C S et al.(2010)Bone marrow mononuclear cell therapy led to alveolar-capillary membrane repair, improving lung mechanics in endotoxin-induced acute lung injury. Cell Transplant 19: 965-971.

79. Abreu SC, Antunes MA, Pelosi P, Morales MM, Rocco PR (2011) Mechanisms of cellular therapy in respiratory diseases. Intensive Care Med 37: 1421-1431.

80. Fang X, Neyrinck AP, Matthay MA, Lee JW (2010) Allogeneic human mesenchymal stem cells restore epithelial protein permeability in cultured human alveolar type II cells by secretion of angiopoietin-1.J Biol Chem 285: 26211-26222.

81. Lee JW, Fang X, Krasnodembskaya A, Howard JP, Matthay MA (2011) Concise review: Mesenchymal stem cells for acute lung injury: role of paracrine soluble factors.Stem Cells 29: 913-919.

82. Ott HC, Clippinger B, Conrad C, Schuetz C, Pomerantseva I, et al. (2010) Regeneration and orthotopic transplantation of a bioartificial lung.Nat Med 16: 927-933.

83. Araújo IM, Abreu SC, Maron-Gutierrez T, Cruz F, Fujisaki L, et al. (2010) Bone marrow-derived mononuclear cell therapy in experimental pulmonary and extrapulmonary acute lung injury.Crit Care Med 38: 1733-1741.

84. Chapman H A, Li X, Alexander J P, Brumwell A, Lorizio W, et al.(2011)Integrin alpha6beta4 identifies an adult distal lung epithelial population with regenerative potential in mice. J Clin Invest 121: 2855-2862.

85. Gao J, Dennis JE, Muzic RF, Lundberg M, Caplan Al (2001) The dynamic in vivo distribution of bone marrow-derived mesenchymal stem cells after infusion. Cells Tissues Organs 169: 12-20.

86. Ortiz LA, Gambelli F, McBride C, Gaupp D, Baddoo M, et al. (2003) Mesenchymal stem cell engraftment in lung is enhanced in response to bleomycin exposure and ameliorates its fibrotic effects.Proc Natl Acad Sci U S A 100: 8407-8411.

87. Loi R, Beckett T, Goncz KK, Suratt BT, Weiss DJ (2006) Limited restoration of cystic fibrosis lung epithelium in vivo with adult bone marrow-derived cells.Am J Respir Crit Care Med 173: 171-179.

88. Herzog EL, Krause DS (2006) Engraftment of marrow-derived epithelial cells: the role of fusion.Proc Am Thorac Soc 3: 691-695.

89. Zhang Y, Goss AM, Cohen ED, Kadzik R, Lepore JJ, et al. (2008) A Gata6-Wnt pathway required for epithelial stem cell development and airway regeneration. Nat Genet 40: 862-870. 
90. Cai S X, Liu A R, Chen S, He H L, Chen Q H, et al.(2015)Activation of Wnt/betacatenin signalling promotes mesenchymal stem cells to repair injured alveolar epithelium induced by lipopolysaccharide in mice. Stem Cell Res Ther.6:65.

91. Chen J, Li Y, Hao H, Li C, Du Y, et al.(2015)Mesenchymal Stem Cell Conditioned Medium Promotes Proliferation and Migration of Alveolar Epithelial Cells under Septic Conditions In Vitro via the JNK-P38 Signaling Pathway. Cell Physiol Biochem.37:1830-1846.

92. Aliotta J M, Sanchez-Guijo F M, Dooner G J, Johnson K W, Dooner M S, et al. (2007) Alteration of marrow cell gene expression, protein production, and engraftment into lung by lung-derived microvesicles: a novel mechanism for phenotype modulation. Stem Cells 25: 2245-2256.

93. Quesenberry PJ, Aliotta JM (2008) The paradoxical dynamism of marrow stem cells: considerations of stem cells, niches, and microvesicles.Stem Cell Rev 4: 137-147.

94. Li J, Zhou J, Zhang D, Song Y, She J, et al. (2015) Bone marrow-derived mesenchymal stem cells enhance autophagy via PI3KJAKT signalling to reduce the severity of ischaemia/reperfusion-induced lung injury. J Cell Mol Med 19: 2341-2351.

95. Li L, Li L, Zhang Z, and Jiang Z(2015)Hypoxia promotes bone marrow-derived mesenchymal stem cell proliferation through apelin/APJ/autophagy pathway. Acta Biochim Biophys Sin (Shanghai).47: 362-367.

96. Hong KU, Reynolds SD, Watkins S, Fuchs E, Stripp BR (2004) In vivo differentiation potential of tracheal basal cells: evidence for multipotent and unipotent subpopulations.Am J Physiol Lung Cell Mol Physiol 286: L643-649.

97. Hajj R, Baranek T, Le Naour R, Lesimple P, Puchelle E, et al. (2007) Basal cells of the human adult airway surface epithelium retain transit-amplifying cell properties.Stem Cells 25: 139-148.

98. Hackett TL, Shaheen F, Johnson A, Wadsworth S, Pechkovsky DV, et al. (2008) Characterization of side population cells from human airway epithelium.Stem Cells 26: 2576-2585.

99. Stripp BR, Reynolds SD (2008) Maintenance and repair of the bronchiolar epithelium.Proc Am Thorac Soc 5: 328-333.

100. Gamble JR, Drew J, Trezise L, Underwood A, Parsons M, et al. (2000) Angiopoietin-1 is an antipermeability and anti-inflammatory agent in vitro and targets cell junctions.Circ Res 87: 603-607.

101. Pati S, Gerber M H, Menge T D, Wataha K A, Zhao Y, et al. (2011) Bone marrow derived mesenchymal stem cells inhibit inflammation and preserve vascular endothelial integrity in the lungs after hemorrhagic shock. PLoS One 6: e25171.

102. Senoo M, Pinto F, Crum CP, McKeon F (2007) p63 Is essential for the proliferative potential of stem cells in stratified epithelia.Cell 129: 523-536.

103. Kim CF, Jackson EL, Woolfenden AE, Lawrence S, Babar I, et al. (2005) Identification of bronchioalveolar stem cells in normal lung and lung cancer. Cell 121: 823-835

104. Kajstura J, Rota M, Hall SR, Hosoda T, D'Amario D, et al. (2011) Evidence for human lung stem cells.N Engl J Med 364: 1795-1806.

105. Gnecchi M, Zhang Z, Ni A, Dzau VJ (2008) Paracrine mechanisms in adult stem cell signaling and therapy.Circ Res 103: 1204-1219.

106. Mirotsou M, Jayawardena TM, Schmeckpeper J, Gnecchi M, Dzau VJ (2011) Paracrine mechanisms of stem cell reparative and regenerative actions in the heart.J Mol Cell Cardiol 50: 280-289.

107. Tropea KA, Leder E, Aslam M, Lau AN, Raiser DM, et al. (2012)Bronchioalveolar stem cells increase after mesenchymal stromal cell treatment in a mouse model of bronchopulmonary dysplasia.Am J Physiol Lung Cell Mol Physiol 302: L829-837.

108. Fischer U M, Harting M T, Jimenez F, Monzon-Posadas W O, Xue H, et al.(2009)Pulmonary passage is a major obstacle for intravenous stem cell delivery: the pulmonary first-pass effect. Stem Cells Dev.18:683-692.

109. Bentzon J F, Stenderup K, Hansen F D, Schroder H D, Abdallah B M, et al.(2005)Tissue distribution and engraftment of human mesenchymal stem cells immortalized by human telomerase reverse transcriptase gene. Biochem Biophys Res Commun 330: 633-640.

110. Schrepfer S, Deuse T, Reichenspurner H, Fischbein MP, Robbins RC, et al. (2007) Stem cell transplantation: the lung barrier.Transplant Proc 39: 573-576.

111. Choi H, Lee R H, Bazhanov N, Oh JY, and Prockop DJ (2011) Anti-inflammatory protein TSG- 6 secreted by activated MSCs attenuates zymosan-induced mouse peritonitis by decreasing TLR2/NF-kappaB signaling in resident macrophages. Blood 118: 330-338.

112. Lee J W, Krasnodembskaya A, Mckenna D H, Song Y, Abbott J, et al. (2013) Therapeutic effects of human mesenchymal stem cells in ex vivo human lungs injured with live bacteria. Am J Respir Crit Care Med.187:751-760.

113. Guery B P, Mason C M, Dobard E P, Beaucaire G, Summer W R, et al. (1997) Keratinocyte growth factor increases transalveolar sodium reabsorption in normal and injured rat lungs. Am J Respir Crit Care Med 155: 1777-1784

114. Shyamsundar M, McAuley DF, Ingram RJ, Gibson DS, O'Kane D, et al. (2014) Keratinocyte growth factor promotes epithelial survival and resolution in a human model of lung injury.Am J Respir Crit Care Med 189: 1520-1529.

115. Cross L J, O'kane C M, Mcdowell C, Elborn J J, Matthay M A, et al.(2013) Keratinocyte growth factor in acute lung injury to reduce pulmonary dysfunction--a randomised placebo-controlled trial (KARE): study protocol. Trials 14: 51 .

116. Hyatt BA, Shangguan X, Shannon JM (2004) FGF-10 induces SP-C and Bmp4 and regulates proximal-distal patterning in embryonic tracheal epithelium.Am J Physiol Lung Cell Mol Physiol 287: L1116-1126.

117. Benjamin JT, Smith RJ, Halloran BA, Day TJ, Kelly DR, et al. (2007) FGF10 is decreased in bronchopulmonary dysplasia and suppressed by Toll-like receptor activation. Am J Physiol Lung Cell Mol Physiol 292: L550-558.

118. Gupte V V, Ramasamy S K, Reddy R, Lee J, Weinreb P H, et al. (2009) Overexpression of fibroblast growth factor- 10 during both inflammatory and fibrotic phases attenuates bleomycin-induced pulmonary fibrosis in mice. Am J Respir Crit Care Med 180: 424-436.

119. Kim N, Yamamoto H, Pauling MH, Lorizio W, Vu TH (2009) Ablation of lung epithelial cells deregulates FGF-10 expression and impairs lung branching morphogenesis.Anat Rec (Hoboken) 292: 123-130.

120. Feng N, Wang Q, Zhou J, Li J, Wen X, et al.(2016)Keratinocyte growth factor-2 inhibits bacterial infection with Pseudomonas aeruginosa pneumonia in a mouse model. J Infect Chemother.22:44-52.

121. Alderson R, Gohari-Fritsch S, Olsen H, Roschke V, Vance C, et al.(2002)In vitro and in vivo effects of repifermin (keratinocyte growth factor-2, KGF-2) on human carcinoma cells. Cancer Chemother Pharmacol.50:202-212.

122. Tong L, Bi J1, Zhu X, Wang G, Liu J, et al. (2014) Keratinocyte growth factor-2 is protective in lipopolysaccharide-induced acute lung injury in rats. Respir Physiol Neurobiol 201: 7-14.

123. Bi J, Tong L, Zhu X, Yang D, Bai C et al. (2014) Keratinocyte growth factor-2 intratracheal instillation significantly attenuates ventilator-induced lung injury in rats. J Cell Mol Med 18: 1226-1235.

124.Zhu YG, Feng XM, Abbott J, Fang XH, Hao Q, et al. (2014) Human mesenchymal stem cell microvesicles for treatment of Escherichia coli endotoxin-induced acute lung injury in mice.Stem Cells 32: 116-125.

125. Tong L, Zhou J, Rong L, Seeley EJ, Pan J, et al. (2016) Fibroblast Growth Factor-10 (FGF-10) Mobilizes Lung-resident Mesenchymal Stem Cells and Protects Against Acute Lung Injury.Sci Rep 6: 21642.

126. Loebinger MR, Sage EK, Janes SM (2008) Mesenchymal stem cells as vectors for lung disease. Proc Am Thorac Soc 5: 711-716.

127.Zhao YD, Courtman DW, Ng DS, Robb MJ, Deng YP, et al. (2006) Microvascular regeneration in established pulmonary hypertension by angiogenic gene transfer.Am J Respir Cell Mol Biol 35: 182-189.

128. Rock JR, Onaitis MW, Rawlins EL, Lu Y, Clark CP, et al. (2009) Basal cells as stem cells of the mouse trachea and human airway epithelium.Proc Natl Acad Sci U S A 106: 12771-12775.

129. Rock JR, Hogan BL (2010) Developmental biology. Branching takes nerve. Science 329: 1610-1611.

130. Zhao YF, Luo YM, Xiong W, Ding W, Li YR, et al. (2015) Mesenchymal stem cellbased FGF2 gene therapy for acute lung injury induced by lipopolysaccharide in mice.Eur Rev Med Pharmacol Sci 19: 857-865.

131.Zhao YF, Xiong W, Wu XL (2014) Mesenchymal stem cell-based developmental endothelial locus-1 gene therapy for acute lung injury induced by lipopolysaccharide in mice.Mol Med Rep 9: 1583-1589.

132. Saito S, Nakayama T, Hashimoto N, Miyata Y, Egashira K, et al. (2011) Mesenchymal stem cells stably transduced with a dominant-negative inhibitor of CCL2 greatly attenuate bleomycin-induced lung damage. Am J Pathol 179 : 1088-1094. 